\title{
Application of waste oil purification technology on a heating installation of an industrial hall
}

\author{
Mihai Dragne ${ }^{1}$, Elena Pop $^{1 *}$, and Ionel Pîșă ${ }^{1}$ \\ ${ }^{1}$ University Politehnica of Bucharest, Faculty of Mechanical Engineering and Mechatronics, \\ Department of Thermodynamics, Engines, Thermal and Refrigeration Equipment, Splaiul \\ Independentei, 313, Romania;
}

\begin{abstract}
The paper proposes the development of an experimental model of boiler using waste oil revitalized with bentonite, for heating an industrial hall. The main objective is to present a new perspective on the use of waste oils, a framework in which it no longer presents a danger to the environment and to human health, as well as their energy use from an economic and ecological point of view. Experiments were performed to determine the adsorption of the impurities from the waste oil. One of the experiments is to compare the combustion of the revitalized waste oil with the combustion of raw waste oil. The results show improvements in the combustion process and decreases of the pollutant emissions for revitalized waste oil. The CO concentration decreased on average by $52 \%$ when and the NOx concentration increased by $57 \%$ due to the increase of temperature in the furnace in the case of burning purified oil. The experimental installation is adapted on an industrial hall.
\end{abstract}

\section{Introduction}

Waste oils are a more attractive raw material for obtaining basic oils than the corresponding fractions in the oil, because the yield is higher and does not require extraction or solvent deparaffining. However, the processing of waste oils is having great difficulties and more and more complex technologies have been developed that take into account the type and degree of impurity of the waste oil [1]. An important benefit of the treatment-revitalization of waste oils is the elimination of a complex source of pollution and the return to the consumption of a combustible material [2]. The application of the research results will contribute to ensuring a sustainable economic development at the project field level. This promotes the exploitation and use of the deposits of natural absorbents (bentonites) and the use of waste energy resources while saving the classical resources. As a result of the investments for the exploitation and use in the project field of the natural deposits of absorbents, there will be an economic development of the area, which will lead to the improvement of the living and health conditions of the local population [3].

\section{Experimental determinations}

* Corresponding author: elena.pop@upb.ro 


\subsection{Materials and methods}

From the analysis of waste oils (from both spark-ignition engine and compression ignition engine), the initial concentration of metal ions is between 50 and $200 \mathrm{mg} /$ liter, predominantly iron $(\mathrm{Fe})$. The next step was mixing the used oil with bentonite in 4 concentrations, respectively adding $20 \mathrm{~g}, 40 \mathrm{~g}, 60 \mathrm{~g}, 80 \mathrm{~g}$ bentonite / liter. The mixture was made with an electric mixer, about 30 minutes, for 3-4 days in a row [4]. After mixing, the impurities adsorbed by bentonite were retained. The following experiment was conducted at the National Center for Micro and Nanomaterials (C.N.M.N.), the structural analysis laboratory within the University Politehnica of Bucharest (U.P.B.). After mixing, the bentonite adsorbed metal ions and by filtration the solid matter was removed. The mixing time was not monitored in these experiments. The solid sample containing bentonite who absorbed metal ions was burned for 2 hours at 815 degrees Celsius. We then performed the elemental analysis of ash using an Agilent 8800 Inductive Coupled Plasma Mass Spectrometry (ICP-MS) equipment (Agilent Technologies, Japan). Prior to the measurements at the ICP-MS, the samples were individually weighed and placed in special tubes. After the addition of $2 \mathrm{ml}$ of $\mathrm{HNO} 3$, the samples were digested in a microwave system (Milestone Ethos, FKV, Bergamo, Italy), at $200^{\circ} \mathrm{C}$ for 35 minutes, maximum power of $1800 \mathrm{~W}$. After cooling, the digestion fluids were diluted with ultrapure water to $25 \mathrm{ml}$. The measurements were made for the most abundant isotopes of each element.

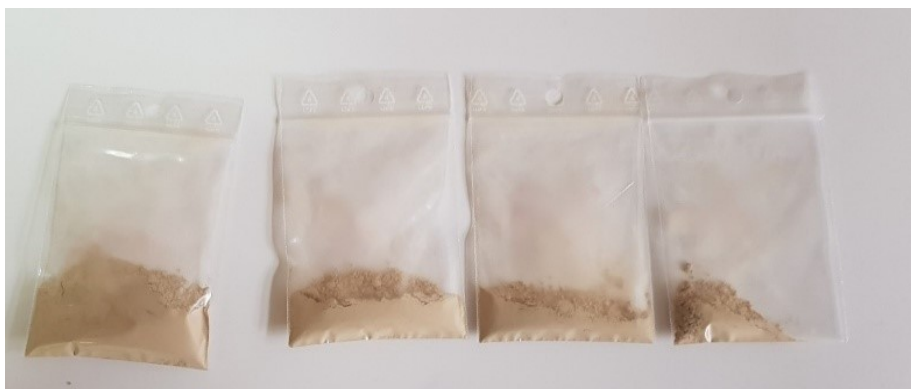

Fig.1 The ash samples of the bentonite that adsorbed the impurities in the waste oil for the four cases considered

\subsection{Determination of impurities removed from waste oil using bentonite}

From the experiment presented above we obtained the following results presented in the table below:

Table 1 The results from the analysis of the ash of bentonite mixed with the used oil

\begin{tabular}{|c|c|c|c|c|c|c|}
\hline $\begin{array}{c}\text { Sample } \\
\text { type }\end{array}$ & $\begin{array}{c}\text { Sample } \\
{[\mathrm{g}]}\end{array}$ & $\begin{array}{c}56 \mathrm{Fe} \\
{[\mathrm{mg} / \mathrm{g}]}\end{array}$ & $\begin{array}{c}63 \mathrm{Cu} \\
{[\mathrm{mg} / \mathrm{g}]}\end{array}$ & $\begin{array}{c}66 \mathrm{Zn} \\
{[\mathrm{mg} / \mathrm{g}]}\end{array}$ & $\begin{array}{c}111 \mathrm{Cd} \\
{[\mathrm{mg} / \mathrm{g}]}\end{array}$ & $\begin{array}{c}208 \mathrm{~Pb} \\
{[\mathrm{mg} / \mathrm{g}]}\end{array}$ \\
\hline B $20 \mathrm{~g}$ & 0.1009 & 63.24 & 0.077 & 9.8 & 0.0012 & 0.122 \\
\hline B $40 \mathrm{~g}$ & 0.1005 & 75.24 & 0.058 & 10.5 & 0.00078 & 0.178 \\
\hline B $60 \mathrm{~g}$ & 0.0999 & 71.16 & 0.043 & 9.4 & 0.00091 & 0.101 \\
\hline B $80 \mathrm{~g}$ & 0.1002 & 71.93 & 0.046 & 9.8 & 0.0011 & 0.482 \\
\hline
\end{tabular}

It is noticed that the amount of zinc $[\mathrm{Zn}]$, copper $[\mathrm{Cu}]$, cadmium[Cd] and lead[Pb], are small ratios compared to iron [Fe], which is found in quite large quantities. It turns out that $20 \mathrm{~g}$ bentonite /liter waste oil is optimal for copper $(\mathrm{Cu})$, zinc $(\mathrm{Zn})$, cadmium $(\mathrm{Cd})$, lead $(\mathrm{Pb})$ removal and $40 \mathrm{~g}$ bentonite / liter waste oil for iron $(\mathrm{Fe})$ removal. By eliminating the metal 
ions, which are found in the highest proportions in the waste oil, we increase the life of the injector nozzle, which will no longer be impacted by these metal ions.

\subsection{Tests for combustion processes to a pilot boiler}

The experimental tests in the previous research [4] were continued for new results. The experiments were carried out on raw waste oil from the automotive field and revitalized waste oil with bentonite, also from the automotive field, by combustion first on a laboratory pilot boiler of $55 \mathrm{~kW}$. The boiler is equipped with a special burner for liquid which ensures the preheating of the fuel up to $80^{\circ} \mathrm{C}$. For the experiments, the case of mixture of $30 \mathrm{~g}$ bentonite/liter waste oil was chosen considering as an optimal range value between analyzed cases of $20 \mathrm{~g}$ bentonite/liter and $40 \mathrm{~g}$ bentonite/liter, in order to have a balance in the adsorption of all metals from used oil.

The characteristics of the measurements regarding the fuel oil waste and the revitalized waste oil combustion are included in the tables below:

Table 2 Measurements of raw used oil pollution by combustion

\begin{tabular}{|c|c|c|c|c|c|c|c|c|c|}
\hline Sample & $\mathrm{O}_{2}$ & $\mathrm{CO}$ & $\mathrm{CO}_{2}$ & $\mathrm{NO}$ & $\mathrm{NO}_{2}$ & $\mathrm{SO}_{2}$ & $\mathrm{NOx}$ & t gas & $\lambda$ \\
\hline & $\%$ & $p p m$ & $\%$ & $\mathrm{ppm}$ & $\mathrm{ppm}$ & $\mathrm{ppm}$ & $\mathrm{ppm}$ & ${ }^{\circ} \mathrm{C}$ & \\
\hline 1 & 17.3 & 1628 & 2.7 & 11 & 0 & 0 & 11 & 238 & 5.68 \\
\hline 2 & 17.3 & 1722 & 2.7 & 14 & 0 & 0 & 14 & 238 & 5.68 \\
\hline 3 & 17.2 & 1813 & 2.8 & 15 & 0 & 0 & 15 & 242 & 5.53 \\
\hline
\end{tabular}

Table 3 Measurements of used oil revitalized with $30 \mathrm{~g}$ bentonite/liter pollution by combustion

\begin{tabular}{|c|c|c|c|c|c|c|c|c|c|}
\hline Sample & $\mathrm{O}_{2}$ & $\mathrm{CO}$ & $\mathrm{CO}_{2}$ & $\mathrm{NO}$ & $\mathrm{NO}_{2}$ & $\mathrm{SO}_{2}$ & $\mathrm{NOx}$ & t gas & $\lambda$ \\
\hline & $\%$ & $p p m$ & $\%$ & $\mathrm{ppm}$ & $\mathrm{ppm}$ & $\mathrm{ppm}$ & $\mathrm{ppm}$ & ${ }^{\circ} \mathrm{C}$ & \\
\hline 1 & 16.9 & 1172 & 3 & 28 & 4 & 0 & 32 & 280 & 5.12 \\
\hline 2 & 16.9 & 1293 & 3 & 27 & 4 & 0 & 31 & 278.3 & 5.12 \\
\hline 3 & 17.4 & 1277 & 2,6 & 20 & 4 & 0 & 24 & 263.3 & 5.83 \\
\hline
\end{tabular}

Pollutant emissions, flue gas temperature (t gas) and the excess air $(\lambda)$ at the end of the process has been monitored.

\subsection{Experimental installation on an industrial hall}

The experimental data obtained in the laboratory, on pilot plant, has been transferred to an industrial installation, having at our disposal a company that deals in the automotive field (repairs and overhauls of road vehicles) [5]. A heating system for the two halls of the company, using the revitalized used engine oil, has been designed. For this purpose, the heat losses, the heat requirement, the fuel flow has been calculated. At a yield of $90 \%$, it has an hourly consumption of $4.2 \mathrm{~kg} / \mathrm{h}$ of revitalized used oil. For the entire heating period (November - March) approximately 4 tones of revitalized used oil is required.

About a year ago the boiler (Hiton) was purchased in the industrial hall and the first experiment was done using raw waste oil. A year later the experiment was carried out on the same boiler, but this time using 5 liters of waste oil treated with $150 \mathrm{~g}$ of bentonite meaning $30 \mathrm{~g}$ bentonite/liter waste oil (the same fuel like in laboratory experiment) [6]

The installation on which the experiment was performed is a Hiton HP-145 used oil boiler with $42 \mathrm{~kW}$ thermal power. The boiler is equipped with a burner for liquid which ensures 
the preheating of the fuel up to $40^{\circ} \mathrm{C}$. Once the burner is heatedup to $40^{\circ} \mathrm{C}$ the joints of thermostat placed next to combustion chamber clutch activating the oil inlet pipeand fans.

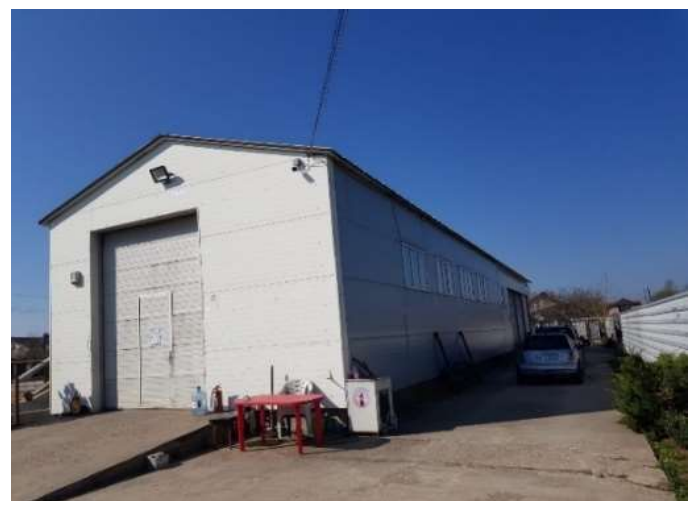

Fig.2 Industrial hall on which the experiment was carried out

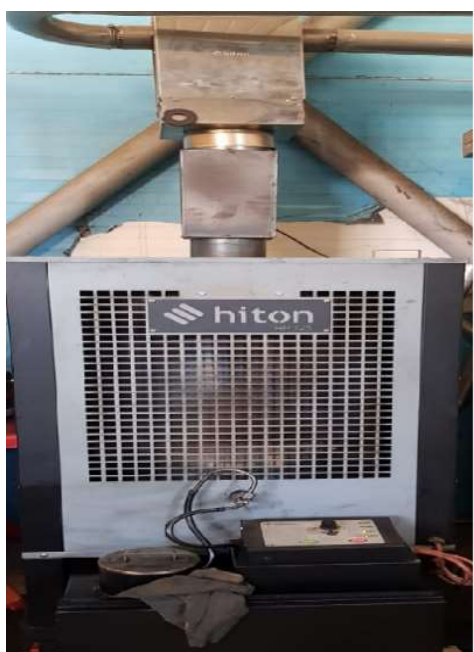

Fig.3 The boiler on which the experiments were performed

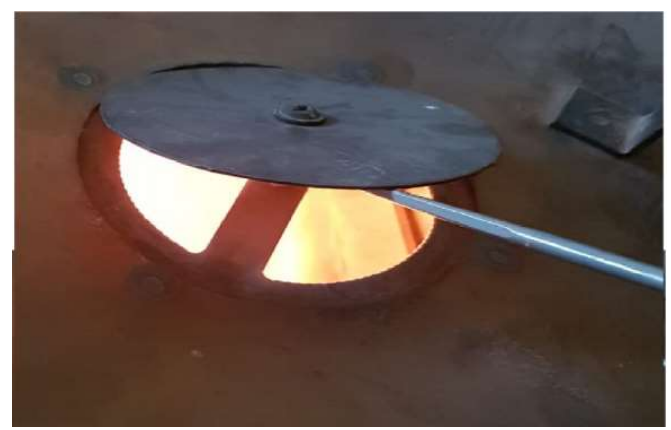

Fig.4 Aspect of flame inside the boiler furnace

The results are present in tables below: 
Table 4 Polluting emissions by combustion of raw used oil, dated 14.01.2019

\begin{tabular}{|c|c|c|c|c|c|c|c|c|c|}
\hline Sample & $\mathrm{O}_{2}$ & $\mathrm{CO}$ & $\mathrm{CO}_{2}$ & $\mathrm{NO}$ & $\mathrm{NO}_{2}$ & $\mathrm{SO}_{2}$ & $\mathrm{NOx}$ & t gas & $\lambda$ \\
\hline & $\%$ & $\mathrm{ppm}$ & $\%$ & $\mathrm{ppm}$ & $\mathrm{ppm}$ & $\mathrm{ppm}$ & $\mathrm{ppm}$ & ${ }^{\circ} \mathrm{C}$ & \\
\hline 1 & 12.8 & 169 & 6.1 & 33 & 0 & 0 & 33 & 179 & 2.56 \\
\hline 2 & 12.9 & 170 & 6.1 & 34 & 0 & 0 & 34 & 178 & 2.56 \\
\hline 3 & 12.7 & 168 & 6.1 & 33 & 0 & 0 & 33 & 180 & 2.56 \\
\hline
\end{tabular}

Table 5 Polluting emissions by combustion of purified oil treated with $30 \mathrm{~g}$ bentonite / liter, 10.03.2020

\begin{tabular}{|c|c|c|c|c|c|c|c|c|c|}
\hline Sample & $\mathrm{O}_{2}$ & $\mathrm{CO}$ & $\mathrm{CO}_{2}$ & $\mathrm{NO}$ & $\mathrm{NO}_{2}$ & $\mathrm{SO}_{2}$ & $\mathrm{NOx}$ & t gas & $\lambda$ \\
\hline & $\%$ & $\mathrm{ppm}$ & $\%$ & $\mathrm{ppm}$ & $\mathrm{ppm}$ & $\mathrm{ppm}$ & $\mathrm{ppm}$ & ${ }^{\circ} \mathrm{C}$ & \\
\hline 1 & 14.1 & 91 & 5.4 & 51 & 0 & 0 & 51 & 200 & 3.04 \\
\hline 2 & 13.7 & 94 & 5.2 & 52 & 0 & 0 & 52 & 196 & 2.88 \\
\hline 3 & 13.9 & 76 & 5.3 & 51 & 0 & 0 & 51 & 198 & 2.96 \\
\hline 4 & 13.6 & 92 & 5.0 & 53 & 0 & 0 & 53 & 197 & 2.84 \\
\hline
\end{tabular}

The boiler is always designed to maintain a constant temperature, thus reducing fuel consumption. The gas outlet pipe is kept clean due to its inclination; the ash is collected in the tray which must be emptied periodically. Normally, in 30-40 minutes the cleaning is done.

\section{Conclusions}

By analyzing the data from the tables above, the following conclusions can be drawn:

- the CO concentration decreased on average by $52 \%$ when burning the purified oil;

- the NOx concentration increased by $57 \%$ (from $33 \mathrm{ppm}$ to $52 \mathrm{ppm}$ ), due to the increase of the temperature in the furnace to the burning of the purified oil;

- the results obtained in the experiments on the pilot boiler at Politehnica University of Bucharest are comparable with the data obtained at industrial hall on boiler Hiton.

The installation on an industrial hall that has as main source of heating a boiler on waste oil is economically and practically advantageous. This type of heating system is perfect for heating large areas of the following sectors:

- Industry sector: industrial constructions, warehouses of goods, production halls;

- Automotive sector: car depots and car workshops;

- Agriculture sector: agricultural buildings, basements, garages, sports and recreation facilities, tents, churches [7].

Waste oil purification technology presented, compared with technologies like REVIVOILD, BLOWDEC, DUNWELL WFE [8, 9, 10, 11], has the advantage of a very low energy consumption, without involving energy of chemical reaction.

This work was supported by a grand of Romanian Ministry of Research and Innovation, CCCDI e UEFISCDI, project number PN-III-P1-1.2-PCCDI-2017-0404/31PCCDI/2018, within PNCDI III. 


\section{References}

1. C. Stan, C.A.M. Toma, Some aspects of the regeneration of used motor oil, Procedia Manufacturing, Volume 22 (2018) 709-713

2. D.I. Osman, S.K. Attia, A.R. Taman, Recycling of used engine oil by different solvent, Egyptian Journal of Petroleum 27 (2018) 221-225

3. D. A. Ciupăgeanu, G. Lăzăroiu, M. Tîrșu, Carbon dioxide emissions reduction by renewable energy employment in Romania, Proc. of 11 th international conference and electromechanical and power systems SIELMEN, (2017)

4. M. Dragne, E. Pop, C. I. Covaliu, E. Matei, I. Pîșă, Experiments in use of bentonite for energy recovery of used oils, E3S WEB CONF., Volume 122, (2019)

5. J. Zhao, Y. Duan, X. Liu, Study on the policy of replacing coal-fired boilers with gasfired boilers for central heating based on the 3E system and the TOPSIS method: A case in Tianjin China, Energy, Volume 189 (2019)

6. S. Fujii, N. Horie, K. Nakaibayashi, Y. Kanematsu, Y. Kikuchi, T. Nakagaki, Design of zeolite boiler in thermochemical energy storage and transport system utilizing unused heat from sugar mill, Applied Energy, Vol.238, (2019)

7. N. Zhao, B. Li, D. Chen, R. Ahmad, Y. Zhu, G. Li, Z. Yu, J. Li, E. Wang, S. Yun, H. Yoon, Y. Zhou, R. Dong, H. Wang, J. Cao, J. He, X. Ju, Direct combustion of waste oil in domestic stove by an internal heat re-circulation atomization technology: Emission and performance analysis, Waste Management, Volume 104 (2020) 20-32

8. F.D. Giovanna, O. Khlebinskaia, A. Lodolo, S. Miertus, Compendium of used oil regeneration Technologies, Trieste, (2003)

9. C.T. Pinheiro, R.F. Pais, M.J. Quina, L.M. Gando-Ferreira, Regeneration of wastelubrificant oil with distinct properties by extraction-flocculation using green solvents, Journal of cleaner production, Vol. 200 (2018)

10. H. Shabanzade, A. Salem, S. Salem, Management of adsorbent content in waste motor oil regeneration by spectrophotometrical study and effective acidification in production of nano-porous clay, Spectrochimica Act Part A: Molecular and Biomolecular Spectroscopy, Volume 202 (2018)

11. S. Salem, A. Salem, A.A. Babaei, Preparation and characterization of nano porous bentonite for regeneration of semi-treated waste engine oil: Applied aspects for enhanced recovery, Chemical Engineering Journal, Volume 260 (2015) 